Cahiers $d u$ MONDE RUSSE

\section{Cahiers du monde russe}

Russie - Empire russe - Union soviétique et États indépendants

45/3-4 | 2004

Varia

\title{
Gábor T. Rittersporn, Malte Rolf, Jan C. Behrends, eds., Sphären von Öffentlichkeit in Gesellschaften sowjetischen Typs
}

\section{Nathalie Moine}

\section{(2) OpenEdition}

\section{Journals}

Édition électronique

URL : https://journals.openedition.org/monderusse/4192

DOI : 10.4000/monderusse.4192

ISSN : $1777-5388$

Éditeur

Éditions de l'EHESS

Édition imprimée

Date de publication : 1 juillet 2004

Pagination : 674-677

ISBN : 2-7132-2009-2

ISSN : $1252-6576$

Référence électronique

Nathalie Moine, "Gábor T. Rittersporn, Malte Rolf, Jan C. Behrends, eds., Sphären von Öffentlichkeit in Gesellschaften sowjetischen Typs », Cahiers du monde russe [En ligne], 45/3-4 | 2004, mis en ligne le 03 juin 2009, consulté le 03 septembre 2022. URL : http://journals.openedition.org/monderusse/ 4192 ; DOI : https://doi.org/10.4000/monderusse.4192

Ce document a été généré automatiquement le 3 septembre 2022.

Tous droits réservés 


\title{
Gábor T. Rittersporn, Malte Rolf, Jan C. Behrends, eds., Sphären von Öffentlichkeit in Gesellschaften sowjetischen Typs
}

\author{
Nathalie Moine
}

\section{RÉFÉRENCE}

Gábor T. RITTERSPORN, Malte ROLF, Jan C. BEHRENDS, eds., Sphären von Öffentlichkeit in Gesellschaften sowjetischen Typs/Public spheres in Soviet-type societies. Francfort-sur-le-Main, Peter Lang, 2003, 457 p.

Repérer les lieux d'interaction entre les individus, entre les groupes sociaux, entre le peuple et l'État, et ce dans l'ensemble des pays se référant au modèle soviétique, de la révolution d'Octobre à la chute des régimes communistes, tel est l'objet de ce recueil, issu d'une conférence qui s'est tenue en mai 2000 à Berlin.

Étant donné le projet des États de type soviétique d'organiser la vie sociale sous tous ses aspects, la tâche est immense et l'introduction de l'ouvrage ne s'en cache pas, s'attachant cependant à montrer la centralité du questionnement. Il s'agit donc de repenser et de dépasser les questions d'adhésion et d'opposition au régime. Les coordinateurs de la publication n'ont eu de cesse de démontrer que le total conditionnement des individus à l'idéologie imposée par le régime était un fantasme et non une réalité. Pour autant, ils sont convaincus que la question d'être pour ou contre le système ne faisait pas sens pour la plupart des contemporains vivant dans ce type de régime politique. L'étude des modes de socialisation permet de l'expliquer.

L'ensemble de ces processus a pour cadre ce qui est nommé ici sphère publique. Telle qu'elle est utilisée dans le cas présent, cette notion n'a évidemment que peu de chose en commun avec celle élaborée par Jürgen Habermas à propos des sociétés bourgeoises du 
XIxe siècle, et avant lui, celle d'« Öffentlichkeit » dans l'Allemagne des Lumières ; c'est bien d'elle pourtant que sont partis les auteurs pour tenter de comprendre ce que pouvait signifier l'espace public dans un contexte socio-politique de type soviétique. Cette sphère est évidemment privée de liberté d'expression, mais il existe néanmoins des lieux de rencontre et d'échange entre individus, qui y trouvent un ensemble de valeurs, de symboles susceptibles de forger - par adhésion, opposition ou détournement - leur propre vision du monde et les moyens de communiquer avec leurs concitoyens.

Du fait de l'ampleur thématique de ce recueil d'articles, la lecture de l'introduction, mais aussi de la conclusion, s'impose pour saisir le propos d'ensemble, avant de s'aventurer dans les études de cas. Cependant, les diverses contributions permettent de mettre en œuvre ce concept de sphère publique à la soviétique. À vrai dire, la répartition des articles par pays, rédigés pour moitié en allemand, pour l'autre en anglais, ne facilite pas l'émergence des points d'accroche. On tentera d'en proposer quelques-uns, étant entendu que la sphère publique est ici traitée tantôt comme un espace physique, tantôt comme un espace virtuel de type discursif - certaines contributions, mais pas toutes, liant ensemble ces deux notions, notamment dans le cadre de l'espace public saisi à travers une institution.

Une place non négligeable est ainsi accordée à l'espace urbain. On sait, au moins depuis Louis Marin et ses travaux sur l'urbanisme absolutiste, combien l'espace, dans son organisation et son habillage, permet au pouvoir de se mettre en scène et de développer un discours saisissable par tous, dont la place royale est la quintessence. Les contributions sur Moscou, mais aussi sur la ville de Lublin (Izabella Main), ou encore la National Galerie de Berlin (Juliana Raupp), permettent ainsi d'y revenir, et à différentes échelles : construction du décor (l'urbanisme moscovite étudié par Monica Rüthers), lieu d'acculturation (le Parc de loisirs Gorki de Katharina Kucher), lieu de confrontation des symboles (croix catholiques contre drapeaux rouges des manifestants communistes polonais, exposition des artistes de la RDA), jeux d'appropriation, en particulier par le changement des noms de rues et de lieux. Une place à part doit être faite aux pratiques de cohabitation dans les appartements communautaires de Leningrad, qui posent bien évidemment la question de la frontière entre le privé et le public, mais dans un sens distinct des autres contributions, puisque Katerina Gerasimova montre comment l'espace commun n'est pas à proprement parler un lieu de communication, tout en étant un lieu d'apprentissage de la vie en public à la soviétique. Malgré tout l'intérêt de ces analyses, d'autres types d'espaces publics tout aussi importants pour les habitants du second xxe siècle, mais encore peu fréquentés par les historiens, mériteraient d'être étudiés, et la focalisation exclusive sur la grande ville corrigée.

L'espace public peut également être saisi dans un sens plus virtuel. Le meilleur exemple proposé par l'ouvrage est sans doute la présence d'un discours national, thème commun à plusieurs contributions, qui décrivent un ensemble de symboles et de croyances. En partie encouragé et instrumentalisé par le régime lui-même, comme dans la Hongrie de Kadar (Heino Nyyssönen), il peut aussi faire écho à la dissidence politique. En vérité, il est à l'entre-deux, véhiculant des formes héritées du passé non communiste, et empruntant en partie, mais en partie seulement, aux propositions officielles, sans pour autant s'inscrire dans un geste d'opposition.

Une étude de la sphère publique, dès lors qu'elle est envisagée comme un ensemble de symboles et de rites partagés par un public, laisse la place à des formes de cultures alternatives à celle que veut imposer le pouvoir. Cet aspect est essentiellement 
représenté par une institution dont on a effectivement mesuré toute l'importance dans la chute des régimes communistes en Europe de l'Est, à savoir les Églises. Le rôle de la ferveur religieuse et de son expression dans des lieux de rassemblement de fidèles est ainsi montré aussi bien pour les débuts des différentes expériences communistes (le miracle de la Vierge Noire de Lublin à l'été 1949, l'Église hongroise au tournant des années 1940-1950), qu'au fil du temps et en fin de parcours (les Églises évangéliques de RDA étudiées par Michael Haspel). L'Église est sans doute une des sphères publiques alternatives (Gegenöffentlichkeit) les plus puissantes, et en tous les cas perçue comme telle, ce qu'illustre l'exemple de la Hongrie de Rakozy, où l'Église catholique est à la fois tolérée, espionnée et redoutée par le pouvoir qui oscille entre répression violente et offre de compromission pour mieux en juguler l'influence, ramifiée dans l'ensemble du corps social. À tort ou à raison, elle paraît d'autant plus menaçante que le démantèlement des structures rend opaque l'activité de ses anciens membres, d'emblée perçue comme hostile par la Sécurité d'État (Arpad von Klimo).

Cependant, aucune contribution ne propose d'exemple de Gegenöffentlichkeit totalement dissidente, bien que soient évoqués les mouvements artistiques alternatifs de Tchécoslovaquie et de RDA (Dieter Segert), car la sphère publique est aussi affaire de masses. L'accent est davantage mis sur les problèmes posés par les sphères publiques officielles, qui concernent le public le plus vaste et sur le long terme. Comment par exemple faire fonctionner un réseau de correspondants populaires capables de contribuer à la rédaction des grands journaux par l'apport d'informations spontanément récoltées, mais s'inscrivant dans un cadrage idéologique extrêmement rigide (Lorenz Bichler) ? La question est ici posée pour les débuts de la Chine populaire, elle a aussi été étudiée ailleurs à propos de l'URSS de l'entre-deux-guerres. De même pour la pratique de l'autocritique au sein du parti dans l'URSS des années 1930 (Lorenz Erren), transposable sous d'autres cieux.

La culture est à la fois une des composantes proposées à la notion de sphère publique et peut-être, par son caractère englobant, son équivalent, aux yeux de la plupart des auteurs. On peut cependant s'interroger sur le type de culture effectivement couverte. Si la culture savante ou en voie de légitimation apparait bien dans plusieurs articles, de façon générale la place accordée à la culture tant médiatique qu'alternative reste sans doute trop faible. Ainsi, Ingrid Oswald et Viktor Voronkov s'intéressent à l'affadissement progressif du paysage télévisuel dans la Russie des années 1990, et le rôle des médias avant 1989 fait bien partie, théoriquement, du programme de recherche proposé par les éditeurs de l'ouvrage, qui dégagent clairement leur importance dans le travail de communication inhérent à la notion de sphère publique. Les vecteurs de communication de masse sont pourtant encore trop absents des contributions, à l'exception de l'article de José Faraldo qui montre la persistance de mythes nationaux polonais autour de la bataille de Grünewald à travers la culture cinématographique et télévisuelle d'adolescents des années 1960. D'autres pistes apparaissent: la popularité des films de western et les échanges qu'elle occasionne entre Pologne et RDA est ainsi évoquée, mais dans une simple note de bas de page. Pourtant, cet article, les propositions émises par les éditeurs de l'ouvrage, ainsi que le modèle de sphère publique privée proposé par Viktor Voronkov et Ingrid Oswald pour l'URSS post-stalinienne (des milieux underground à la famille, la tusovka ou rencontre informelle, la culture de la blague et le folklore chers à Gábor Rittersporn ${ }^{1}$ ) suggèrent fortement tout l'intérêt de comprendre les systèmes de références populaires, y compris linguistiques, partagées par le plus grand nombre ou par des groupes plus restreints - dans la lignée des travaux de Richard Stites sur l'Union 
Soviétique -, ainsi que les lieux de leur circulation, en particulier pour la période poststalinienne commune à la plupart des contributions ${ }^{2}$.

Une partie des nouveaux horizons promis par Gábor Rittersporn reste donc encore à conquérir et une des forces de l'ouvrage tient à cette incitation ${ }^{3}$.

\section{NOTES}

1. G. T. Rittersporn, «Le régime face au carnaval. Folklore non conformiste en URSS dans les années 1930 », Annales (HSS), 2, 2003, p. 471-496.

2. Pour un rapide inventaire des formes de loisirs populaires dans la société soviétique jusqu'à la perestroikka, voir R. Stites, Russian popular culture : Entertainment and society since 1900, Cambridge, Cambridge University Press, 1992.

3. G. T. Rittersporn, «New horizons : Conceptualizing the Soviet 1930s », Kritika, 2 (2), 2001, p. 307-318. 